converge to heat a tiny target - was only $\$ 30,000$. A senior official values the radiation-temperature diagnostics system, which France will provide at the NIF in exchange for the chamber, at $\$ 1$ million.

Unlike the NIF, which was designed to be fully functional by 2003, the Laser Megajoule will be constructed incrementally, starting with a few lasers firing targets in the chamber borrowed from the United States, and later adding lasers and new target chambers to accommodate higher energies.

Both facilities aim to achieve 'ignition', at which the fusion of deuterium and tritium fuel inside the target provides enough heat to sustain itself for a short period.

France and the United States have been working increasingly closely on using lasers for nuclear weapons physics since they signed an agreement to collaborate on this in 1994. It has been reported that the French demanded the agreement in exchange for making a commitment to stop nuclear testing.

According to Matt Mckenzie, who monitors nuclear weapons research for the Natural Resources Defense Council, a Washington-based environmental group, the collaboration has moved beyond working together on laser equipment to the design of the targets, called hohlraums, which are heated by the lasers to reproduce conditions inside a detonating nuclear weapon.

Both the Laser Megajoule and the NIF are intended primarily to help train nuclear weapons physicists and to simulate conditions inside nuclear weapons. But they will also be used by plasma physicists to explore the feasibility of inertial confinement fusion as an energy source.

Colin Macilwain

\title{
Germany's research agencies open up recruiting practices
}

\section{Munich}

All vacancies for scientific directors at Germany's Max Planck Institutes will in future be advertised, and a worldwide search for new institute heads will be coordinated by central search commissions, announced Hubert Markl, president of the Max Planck Society (MPS), this week.

The reform of the appointment system is one of the moves being taken in response to an external evaluation of Germany's main basic research organizations published last spring (see Nature 399, 395-396; 1999).

More than half of the MPS's 240 scientific directors will retire within the next eight years. "Systematic head-hunting" of leading German and international scientists is to begin at least three years before a director retires, according to Markl.

By increasing centralized control over appointments, the MPS is keen significantly to strengthen its influence on the areas of research at the 80 institutes. Adopting a more strategic approach to research funding was one of the principal suggestions of the international evaluation committee.

As for the Deutsche Forschungsgemeinschaft (DFG), Germany's grants agency for university research, the committee complained that its inflexible and conservative funding policy would tend to block promising new ideas.

After six months of intensive discussions, the MPS and DFG have now accepted in principle to put most of the committee's suggestions into action. But officials at both organizations stress that constant annual increases in their budgets - currently around DM2 billion (US $\$ 1.03$ billion) each

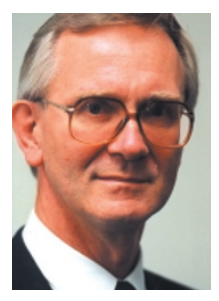

Markl: reform of recruitment

system needed. to cooperate more closely in the training of $\mathrm{PhD}$ students, and to promote innovative interdisciplinary research.

But the MPS added the qualification that the number of additional junior independent research groups at its institutes would be limited by the need to ensure an "appropriately high scientific level", as well as by the lack of "sufficient follow-up positions".

The DFG agreed to revise and speed up its peer-review system. It wants to limit the exclusive right of Germany's scientific societies to nominate referees, in the hope of increasing the number of younger scientists and women among elected referees. But it says it will not introduce a quota system.

The committee had recommended that the DFG should "actively influence the longterm developments of science", rather than just responding to them. But the agency argues that the panel "underestimated the DFG's actual strategic activities”.

The MPS and DFG are calling on the government to help put the reforms into action by providing adequate finance and relaxing restrictive employment laws. Quirin Schiermeier

\section{China and Hong Kong pool effort in high-tech projects}

\section{Beijing}

China's desire to strengthen scientific links with its Hong Kong Special Administrative Region has been confirmed by the announcement of 14 jointly funded research projects.

The Natural Science Foundation of China (NSFC) and the Research Grants Council of Hong Kong (RGC) will finance the research over the next three years. The winning projects were selected from 229 applications by a panel consisting of six experts from the mainland and six from Hong Kong. The work will be funded under a joint research scheme established by the two research councils in November 1998.
Some RMB5 million (US\$604,000) will come from NSFC and HK\$10 million (US\$1.3 million) from RGC each year. The projects are in six fields: new materials, marine and environmental science, life science, management science, information science, and traditional Chinese medicine.

Surprisingly, only one application from the Chinese Academy of Sciences, China's leading research organization, was approved, compared to 11 approved applications from Chinese universities, including the prestigious Beijing University and Tsinghua University.

The NSFC says it has been paying attention to funding scientific exchanges between mainland China and Hong Kong. About 300 such projects were supported by the foundation during 1991-98.

Before the establishment of the joint research scheme, cooperation between the two sides was sporadic and unorganized, without any security for intellectual property, according to Tang Xifang, an official in charge of the scheme at the NSFC.

"The central government asked mainland China to support the scientific research efforts of Hong Kong, so that Hong Kong can become a centre for high-technology development. The establishment of this grant programme is one step taken in response to the government's call," says Tang. Tian Xuewen 